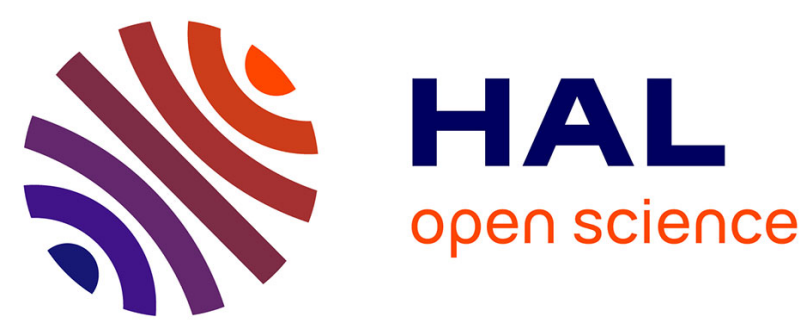

\title{
Design of a Blockchain-Driven System for Product Counterfeiting Restraint in the Supply Chain
}

Sotiris P. Gayialis, Evripidis Kechagias, Georgios A. Papadopoulos, Grigorios

D. Konstantakopoulos

\section{- To cite this version:}

Sotiris P. Gayialis, Evripidis Kechagias, Georgios A. Papadopoulos, Grigorios D. Konstantakopoulos. Design of a Blockchain-Driven System for Product Counterfeiting Restraint in the Supply Chain. IFIP International Conference on Advances in Production Management Systems (APMS), Sep 2019, Austin, TX, United States. pp.474-481, 10.1007/978-3-030-30000-5_59 . hal-02419252

\section{HAL Id: hal-02419252 \\ https://hal.inria.fr/hal-02419252}

Submitted on 19 Dec 2019

HAL is a multi-disciplinary open access archive for the deposit and dissemination of scientific research documents, whether they are published or not. The documents may come from teaching and research institutions in France or abroad, or from public or private research centers.
L'archive ouverte pluridisciplinaire HAL, est destinée au dépôt et à la diffusion de documents scientifiques de niveau recherche, publiés ou non, émanant des établissements d'enseignement et de recherche français ou étrangers, des laboratoires publics ou privés.

\section{(c)(1)}

Distributed under a Creative Commons Attribution| 4.0 International License 


\title{
Design of a Blockchain-driven System for Product Counterfeiting Restraint in the Supply Chain
}

\author{
Sotiris P. Gayialis ${ }^{1}$, Evripidis Kechagias ${ }^{2}$, Georgios A. Papadopoulos ${ }^{3}$ Grigorios D. \\ Konstantakopoulos 4 \\ 1,2,3,4 National Technical University of Athens, School of Mechanical Engineering, \\ Iroon Polytechniou 9, 15780, Athens, Greece \\ ('sotga@central.ntua.gr, ${ }^{1}$ eurikechagias@mail.ntua.gr \\ ${ }^{3}$ gpapado@mail.ntua.gr, ${ }^{4}$ gkonpoulos@mail.ntua.gr)
}

\begin{abstract}
The production and distribution of counterfeited products is an issue for decades in different industry sectors. The trade in fake goods is growing and is affecting the sales and profits of the companies exposed to this phenomenon. It influences governments, world trade, businesses, and consumers, by reducing revenues, economic growth, and consumers' health. This paper aims to present a proposed system for restriction of product counterfeit. This system will be applied in the supply chain of goods, including operations like production, distribution, and sales. In order to ensure the identification and traceability of genuine products throughout the supply chain, the blockchain technology and secure marking techniques of the products will be used. The paper presents the conceptual design of the system, its functionality, the methodological approach for its development and its application in selected industry sectors, as well as the expected results by its use in the supply chain of products.
\end{abstract}

Keywords: Supply Chain, Counterfeit, Fake Products, Blockchain, Information System, Research Project

\section{$1 \quad$ Introduction}

Counterfeiting is defined as the deliberate alteration of the real nature or the originality of a thing for deception purposes, in order to give a misleading impression of facts/evidence/documents/test results [1]. Counterfeiting refers to a wide range of stakeholders in a way that goes beyond the direct impact on legitimate businesses. Consumers who buy these products inadvertently purchase products of inferior quality or safety characteristics and potentially pose severe risks without having the necessary guarantees [2]. Counterfeit traffickers usually do not comply with labor, tax, or trade laws. As a result, governments receive lower tax revenues and eventually increase their spending on welfare, health services, and crime prevention [3]. Even the legitimate businesses operating in an industry where there is intense counterfeiting, are damagingly affected, as the counterfeit products have a significant market share. 
This situation act as a barrier for legitimate competitors to enter the market and get a market share [4].

Product falsification is a vast and ever-increasing phenomenon, as evidenced by the latest available statistics for 2016 collected in a study conducted by the European Patent Office and the Organization for Economic Cooperation and Development. Based on the data for 2016, it is estimated that the volume of international trade in counterfeit products amounted to USD 509 billion, representing 3.3\% of world trade. The previous OECD-EUIPO study, which was based on the same methodology and concerned research into counterfeit products for the year 2013, had concluded that the trade of counterfeit products amounted to $2.5 \%$ of world trade, equivalent to 461 billion US dollars. Counterfeit products can be found in a large and growing number of industries such as consumer goods (footwear, cosmetics, toys), business-to-business products (spare parts or chemicals), IT products (phones, batteries), luxury products (fashion, watches). It is crucial that many counterfeit products, in particular pharmaceuticals, food and beverages, and medical equipment, can pose severe health and safety risks [5].

Every year, 83 billion and 790.000 jobs are missing across the European Union due to counterfeit and pirated products. In particular, as a result of the distribution of these products, more than EUR 48 billion or $7.4 \%$ of sales in 9 sectors are lost, while public revenue losses estimate to 14.3 billion euros (non-payment of income tax, VAT and excise duties). More specifically, in $2017,10 \%$ of EU consumers or about 43 million citizens, were deceived into buying a fake product instead of a genuine one, taking along with all the security risks associated with it [6]. Besides, it should be noted that the EU economy is losing another EUR 35 billion due to the indirect impact of counterfeiting and piracy in these sectors, as manufacturers buy fewer goods and services from suppliers, thus causing knock-on effects to other branches. Lost sales lead to the immediate loss of 500,000 jobs in the specific sectors of the European Union economy as legitimate manufacturers and, in some cases, the distributors of the respective products employ fewer people than they would have if they were not on the market counterfeiting and piracy. Taking into account the knock-on effects of counterfeit products on other sectors, the number of more 290.000 lost jobs has to be taken into account [5].

Especially in Greece, it is estimated that the loss of sales per year due to the illegal trade is about 17 billion Euros, and only by the counterfeiting is 2.1 billion. Losses in euro per capita in Greece are 125 euro. The total number of jobs lost annually due to the trade in counterfeit products is proven to be 24.000 . It is worth noting that Greece ranks 1 st in terms of relative job losses due to the circulation of counterfeit products and fourth in terms of lost sales. Finally, the five sectors with the most significant loss of sales in Greece are medicines, clothing, cosmetics, smartphones, wines and spirits [7].

Thus, the subject of this paper is to present the conceptual design of a new system for product counterfeiting restraint in the entire supply chain. This system incorporates new technology to guarantee the traceability and the identity of genuine products, based on blockchain. 
In the remainder of this paper, the contribution of blockchain technology in modern information systems is presented in Section 2. Section 3 introduces the system's conceptual design and its development approach as part of a research project. In section 4, conclusions and further research are discussed, featuring the next steps of the research in order to develop a blockchain-driven system for product counterfeiting restraint in the supply chain.

\section{Application of Blockchain Technology in the Supply Chain of Products}

In recent years, blockchain technology has begun to be used in many new industrial applications, going beyond its initial application to cryptocurrency [8]. Some great efforts include those of [9-13]. The reasons behind this trend are transparency, security, quality assurance, global peer-to-peer transactions and the decentralization provided by blockchain [14]. In practice, a blockchain is a public, distributed list that contains chain blocks, each of which consists of several transactions. These blocks have been authorized globally and transparently to guarantee security, consisting only of valid and fair transactions. Blocks are shared and synchronized between nodes through a peer-to-peer, distributed and decentralized structure [15]. Despite the potentiality offered by this technology, its integration into the supply chain to counter anticounterfeiting has not yet been widely exploited [16]. The challenge of the new system is to take advantage of this promising technology to combat counterfeiting, aiming essentially to turn the centralized supply chain to a new, decentralized one. The aim of the new system is the creation of a blockchain-based system to restrict counterfeiting in the supply chain of different kind of products.

The system will consist of a product traceability platform as well as a multilayer blockchain platform. The system will focus on the categories of products that are most frequently counterfeited and consumed by people, such as food and beverages. This category of fake products can shave serious health risks, except for financial damage of their legitimate producer and distributor. The primary solution to the problem of counterfeiting, introduced by blockchain technology, is radically redesigning traceability of the supply chain. The decentralized database offered by blockchain technology will be able to store any transaction or activity in the supply chain, thus offering increased recognition capability, traceability and security. Each step along the supply chain will contribute by providing data to a decentralized and secure network that can prove the originality of the product, identifying whom it belongs to and providing authentication. The system will also provide the ability to monitor each product by assigning a unique ID for each piece. To achieve this, appropriate techniques will be developed to link the system to the packaging of the product. This set of data will allow for the detection of all product-related information across the supply chain, thus ensuring its transparency and adequate counterfeit protection. 


\section{An Information System for Counterfeiting Restraint}

\subsection{Methodological Approach for System Development}

This paper presents the ongoing work and the initial results of a research project in Greece. The implementation methodology followed is based on two main phases. The first phase is to explore and evaluate system requirements, methods, and techniques that will be implemented to confront product counterfeiting and link the blockchain based system to product packaging, as well as the integration of blockchain technology for traceability and data security. Finally, this phase includes the detailed specifications of the new system. The second phase is the development, testing, and validation of the original system under real-world conditions in a specific industry. The industry sector of food and beverages has been selected for the system's validation, focusing on alcoholic and non-alcoholic drinks that are commonly counterfeited. The research project's methodology is presented in Figure 1, including the two phases as mentioned above and their main activities.

More specifically, in the first phase, a detailed review of the research field on the problem of counterfeiting of products, focusing on food and beverages, is held. This product category is often subjected to such counterfeits with both economic and consumer health implications. Methods and techniques for linking the system to product packages are also considered so that each product can be detected separately within the supply chain. At the same time, methods and techniques are explored to incorporate blockchain technology for better and safer data management and sharing. Next, the analysis that has been done in conjunction with the examination of a set of real traceability problems leads to the development of the business process for use-cases and the design of specifications. The next step is a more detailed assessment and analysis of the methods and techniques identified in the literature review and field research to identify the aspects and techniques that match the problem of counterfeit products. At the same time, the choice of IT technologies for usage in the development of the system, as well as the integration of blockchain technology are finalized in order to securely and transparently manage and store the data obtained throughout the supply chain.

In the second phase, all the selected methods and techniques are implemented in integrated software, utilizing contemporary IT technologies. This software can ensure safe and original products distribution in the food and beverage supply chain. As a result, the system under development will be used as a decentralized platform, accessible and remotely controlled, which will operate and provided as "Software as a Service" solution. Then, methods and techniques against counterfeiting, methods for linking product packaging, techniques for integrating blockchain technology into the system (for better and safer data management and sharing), as well as the developed software, will be tested in business processes in food and beverage supply chain. Through the development of simulation scenarios in specific companies participating in the supply chain, the effectiveness of the selected methods and techniques will be tested. 


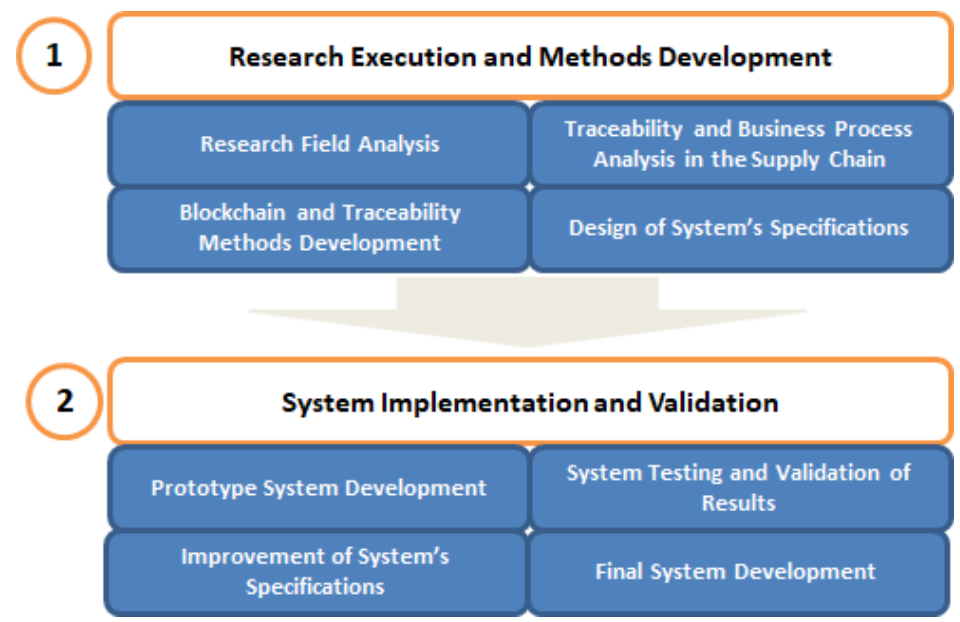

Fig. 1. Research Project's Phases for System Development

\subsection{System's Functionality}

The final software solution is based on the cloud computing concept, as the system runs on the cloud under the responsibility of the system provider. Every user of the blockchain-based system for product counterfeiting restraint can access its functionality as a software service. The producer can generate a unique product ID, which can be traced until the latest part of the supply chain (the consumer). Every part of the supply chain can add in this ID the different states of the product (warehousing, distribution, sale) using the blockchain technology in order to guarantee the safety of data and the authenticity of the product.

The system will also guarantee accurate traceability of the products. Once produced, they will be registered on the traceability platform, from which they can then be traced, identified and updated at each stage of their journey. The platform will allow trading partners to share information about physical movements and product status as they travel across the supply chain, from business to business to the final consumer. The goal of the platform will be to allow dissimilar and distinct applications and processes (as is usually the case between business) to create and communicate events both internally (on-premise) and externally (with their partners). This event data exchange will aim to allow users to gain a common view of physical or digital objects within the company's context. Since the ownership of products is changing along the supply chain, its ownership will be transferred along the blockchain platform. Along with this technology, the necessary data of the products will be recorded, from their production until they reach the retailer. 


\subsection{System's Blockchain Advantages}

First research results for decentralized data management and sharing, like Simple Public Key Infrastructure, were developed in the late 1990s, but they were not deployed. However, with the success of BitCoin and Ethereum, decentralized solutions have now become widely accepted. In this new situation, the new system can achieve real decentralization and can implement security solutions that do not require any "root of trust," by leveraging the blockchain technology. This is not just a theoretical advantage, but a critical property that will increase trust and allow fast adoption by companies.

In order to support data authority and privacy, the system adopts a multi-level approach to the storage of data, including private and public data storage approaches. It includes a private data store managed entirely by the stakeholder, a private blockchain for another level of data storage, containing data that is shared between collaborating stakeholders (for example producer, resellers and retailers in the food and beverages supply chain). Also, data can also be shared and stored in a public blockchain like BitCoin or Ethereum. Thus, the system will guarantee the authenticity of a product, keeping personal data safe and without any compromise on privacy. In this way, the products can be traced without the need for publishing confidential information.

\subsection{Expected Results}

The new system aims at the long-term and medium-term objectives. The main objectives and expected results at the medium-term level include:

1) To offer improved detection and prevention of counterfeiting of the products.

2) To support extended visibility of the products, from its source to the final consumer throughout the supply chain.

3) To increase the trust of participants in the supply chain and effectively deal with data management and sharing, avoiding interception.

4) To lead the transformation of existing business models or create new business models to provide innovative services and products that support modern supply chain business processes.

The long-term level objectives and results of the system include:

1) To contribute effectively in reducing the financial losses suffered by the Greek and other economies, as a result of the counterfeiting of products.

2) To eliminate serious health risks associated with counterfeiting of products consumed by people (like food and beverages), in addition to the economic losses by companies and governments. According to the statistics, the food and beverages industry sector belong to the five industry sectors in Greece with the most significant loss of sales due to counterfeiting.

\section{Conclusions}

This paper presents the development phases and the conceptual design of an integrated web-based software solution to support product counterfeiting restraint within the 
supply chain. Counterfeit products range from high-end consumer luxury goods such as watches, perfumes or leather goods, to business-to-business products such as machines, chemicals or spare parts, to conventional consumer products such as toys, pharmaceuticals, cosmetics, and foodstuffs. In fact, any intellectual property protected product can be counterfeited [17]. Some counterfeit products, such as pharmaceuticals, spare parts, and toys, could be of low quality and thus create significant health and safety threats. The proposed system can contribute to the immediate alignment with the overall efforts of the European Union countries to restrict and eventually eliminate the counterfeit of products.

The software is based on blockchain technology for safer decentralized data management and data sharing within the supply chain. The software will be offered as a Software as a Service to its business users. The anti-counterfeiting system will be implemented in the food and beverage supply chain, covering the need for advanced tools and methods to support the traceability process of modern products. The system can assist producers of goods, wholesalers, distributors, retailers, and consumers in preventing the counterfeit. Every involved part in the supply chain can gain access to the product's data and ID to ensure that it is original and safe. This access to data can be achieved through blockchain technology and advanced technological solutions. The key stakeholders of the system are the producers of goods and their consumers, but every part of the supply chain can benefit the advantages of the new system.

Acknowledgments. The present work is co-funded by the European Union and Greek national funds through the Operational Program "Competitiveness, Entrepreneurship and Innovation" (EPAnEK), under the call "RESEARCH-CREATE-INNOVATE" (project code: T1EDK-00527 and Acronym: SMARTRANS).

\section{References}

1. Babiniotis, G.: Dictionary of the New Greek Language. 4th Edition. Center for Lexicology (2012)

2. Yao, J.T.: The Impact of Counterfeit-Purchase Penalties on Anti-Counterfeiting under Deceptive Counterfeiting. Journal of Economics and Business, vol. 80, pp.51-61 (2015). doi: 10.1016/j.jeconbus.2015.04.002

3. Wilcock, A.E. and Boys K.A.: Reduce Product Counterfeiting: An Integrated Approach. Business Horizons, vol. 57, No. 2, pp.279-88 (2014). doi: 10.1016/j.bushor.2013.12.001

4. Meraviglia, L.: Technology and Counterfeiting in the Fashion Industry: Friends or Foes? Business Horizons, vol. 61, No. 3, pp.467-75 (2018). doi: 10.1016/j.bushor.2018.01.013

5. OECD/EUIPO.: Illicit Trade Trends in Trade in Counterfeit and Pirated Goods (2019). https://euipo.europa.eu

6. EUIPO/EUROPOL.: Situation Report on Counterfeiting and Piracy in the European Union (2017). https://www.europol.europa.eu

7. OECD/EUIPO.: Trade in Counterfeit and Pirated Goods: Mapping the Economic 
Impact (2016). https://euipo.europa.eu

8. Hackius, N. and Petersen, M.: Blockchain in Logistics and Supply Chain: Trick or Treat? Proceedings of the Hamburg International Conference of Logistics (HICL) (2017). In: Kersten, W., Blecker, T., Ringle, C.M.: Digitalization in Supply Chain Management and Logistics. Epubli (2017). doi: 10.15480/882.1442

9. Bocek, T., Rodrigues, B.B., Strasser, T. and Stiller, B.: Blockchains Everywhere - A Use-Case of Blockchains in the Pharma Supply-Chain. In: IFIP/IEEE Symposium on Integrated Network and Service Management (IM), pp.772-77 (2017). doi: 10.23919/INM.2017.7987376

10. Kim, H.M. and Laskowski, M.: Toward an Ontology - Driven Blockchain Design for Supply - Chain Provenance. In: Intelligent Systems in Accounting, Finance and Management, vol. 25, No. 1, pp.18-27 (2018). doi: 10.1002/isaf.1424

11. Madhwal, Y. and Panfilov, P.: Blockchain And Supply Chain Management: Aircrafts' Parts' Business Case. In: Proceedings of the 28th DAAAM International Symposium, pp.1051-1056, B. Katalinic (Ed.), Published by DAAAM International, ISBN 978-3-902734-11-2, ISSN 1726-9679, Vienna, Austria. doi: 10.2507/28th.daaam.proceedings.146

12. Tian, F.: An Agri-Food Supply Chain Traceability System for China Based on RFID \& Blockchain Technology. In: 13th International Conference on Service Systems and Service Management (ICSSSM), pp.1-6 (2016). doi: 10.1109/ICSSSM.2016.7538424

13. Tseng, J.H., Liao, Y.C.. Chong, B. and Liao, S.W.: Governance on the Drug Supply Chain via Gcoin Blockchain. In: Int. J. Environ. Res. Public Health, vol. 15 (2018). doi: 10.3390/ijerph15061055

14. Olleros, F.X. and Zhegu, M.: Research Handbook on Digital Transformations. Edward Elgar Publishing (2016)

15. Mackey, T.K. and Nayyar, G.: A Review of Existing and Emerging Digital Technologies to Combat the Global Trade in Fake Medicines. In: Expert Opinion on Drug Safety, vol. 16, No. 5, pp.587-602 (2017). doi: 10.1080/14740338.2017.1313227

16. Alzahrani, N. and Bulusu, N.: Securing Pharmaceutical and High-Value Products against Tag Reapplication Attacks Using NFC Tags. In: IEEE International Conference on Smart Computing (SMARTCOMP), pp. 1-6 (2016). doi: 10.1109/SMARTCOMP.2016.7501715

17. EUIPO/EUROPOL.: Counterfeiting and Product Piracy (2019). https://www.europol.europa.eu/ 